\title{
Therapeutic approach in monosymptomatic nasal obstruction
}

\author{
Raluca Enache, Dorin Sarafoleanu \\ ENT Sarafoleanu Medical Clinic, Bucharest, Romania
}

\section{ABSTRACT}

The term monosymptomatic nasal obstruction does not refer to the isolated nasal obstruction, but to a nasal pathology in which nasal obstruction is the predominant symptom. Four nasal structures may be involved in the isolated monosymptomatic nasal obstruction: the inferior nasal turbinates, the nasal septum or the nasal valve. Since the phenomenon of nasal obstruction can be due to various diseases, correct assessment of the patient is very important. Correctly performed anamnesis and clinical and paraclinical evaluations can help determine the definite diagnosis and choose the therapeutic strategy indicated in each individual case.

In this review the authors present the proper therapeutic approach for each type of monosymtpomatic nasal obstruction, emphasizing the need of a preoperatory detailed and correct investigation and diagnosis.

KEYWORDS: monosymptomatic nasal obstruction, inferior nasal turbinates, nasal septum, the nasal valve phenomenon

\section{INTRODUCTION}

The term monosymptomatic nasal obstruction does not refer to the isolated nasal obstruction, but to a nasal pathology in which nasal obstruction is the predominant symptom. From a clinical point of view, the obstructive phenomenon may be associated with rhinorrhea, sneezing, smell disorders (hyposmia, anosmia), craniofacial pain syndrome, or nosebleeds ${ }^{1-3}$.

Four nasal structures may be involved in the isolated monosymptomatic nasal obstruction: the inferior nasal turbinates, the nasal septum or the nasal valve (the alar cartilages).

The most frequent cause of nasal obstruction without a deviated septum is the inferior nasal turbinates hypertrophy $y^{4,5}$. The inferior nasal turbinates are involved in the alternating nasal obstruction, the phenomena being accentuated in dorsal decubitus position. The influence of posture on nasal breathing is a very well known phenomenon and it is due to the hydrostatic component ${ }^{6,7}$. Physiologically, when the patient sleeps on the left side, nasal resistance and implicitly nasal obstruction are increased in the left nasal fossa, and vice versa. This phenomenon is known as "paradoxical nasal obstruction" or "body-nose reflex" and occurs in response to an uneven pressure on the body, thus interrupting the nasal cycle $e^{6,8,9}$.

Nasal obstruction due to a septal deviation is unilateral, has a permanent character and it is not influenced by the decongestant treatment of the nasal mucosa.
The nasal valve and the alar cartilages produce a unilateral or bilateral nasal obstruction; in the patient's history, there is a traumatic antecedent or a surgical intervention or an anatomical conformation without aesthetic deficit (the most frequent) (e.g. rhinoplasty). By elevating the nose tip or by performing the Cottle maneuver, nasal obstruction is substantially diminished.

\section{PHYSIOLOGY OF NASAL BREATHING}

In order to understand the involvement of nose structures in the occurrence of monosymptomatic nasal obstruction, it is necessary to know the physiology of nasal breathing.

Upon entering the nasal vestibule, the airflow has a speed of 2-3 m/s, at this level the area being of approximately $90 \mathrm{~mm}^{2}$. Moving forward towards the nasal valve area, the airflow speed reaches $12-13 \mathrm{~m} / \mathrm{s}$, the area being of $30 \mathrm{~mm}^{2}$. The smaller the surface of the area through which a certain volume of air or liquid passes, the higher the speed of the respective volume. This Venturi effect may explain the phenomenon of collapse of the nasal valve. After passing this segment, the airflow reaches the nasal cavity where the area is of $130 \mathrm{~mm}^{2}$, and the speed of the airflow speed decreases to $2-3 \mathrm{~mm} / \mathrm{s}^{6,10}$.

At the level of the nasal cavity, the airflow should have a laminar flow, which is due to the structural 
component of the nasal fossa, respectively the nasal septum and the nasal turbinates.

This laminar flow favours the contact of the air with the entire surface of the nasal mucosa, thereby intervening in the process of humidification and heating of the airflow, in its filtration, as well as in olfaction (odorivector pheromone carriers particles).

The air filtration process is particularly important. Any particle inhaled in the respiratory process is retained by the vibrissae in the nasal vestibule, as well as by the mucus layer in the nasal respiratory mucosa. By mucociliary clearance (MCC), these particles are moved towards the rhinopharynx, then to the esophagus, in the end reaching the gastrointestinal tract.

The main role of MCC is to retain microparticles, but also certain substances, and thus, to prevent them from reaching the lungs. A normal MCC must not exceed 20 minutes ${ }^{11}$. Optimal functioning occurs at a temperature of $37 \mathrm{C}^{\circ}$ and a relative humidity of $100 \%$ (absolute humidity of $44 \mathrm{mg} / \mathrm{dm} 3)^{12}$. Any variation of environmental factors can lead to a change in MCC. A very low temperature associated with a lack of humidity results in the interruption of mucociliary transport, thus favouring bacterial colonization. On the other hand, a high humidity factor significantly improves mucociliary transport ${ }^{12}$.

Another cause of modification of mucociliary clearance is represented by inflammatory or infectious rhinosinusal disorders, as well as by certain surgeries. In this regard, Pandya ${ }^{13}$ showed in the study published in 2008 that, if MCC in a normal adult can vary between $7.5-17.9 \mathrm{~mm} / \mathrm{min}$ (average $=12.7)$, and the transport time (MCTT) between 5.6 and 13.4 minutes (average $=9.5$ ), in the case of certain rhinosinusal disorders these parameters increase their values. Therefore, in case of existence of a septal deviation, MCC may vary between 2.3 and $6.6 \mathrm{~mm} / \mathrm{min}$ (average $=4.3$ ) with an average MCTT of 30.2 minutes. In allergic rhinitis, which translates as the hypertrophy of the inferior nasal turbinates mucosa mucosal, MCC varies be-

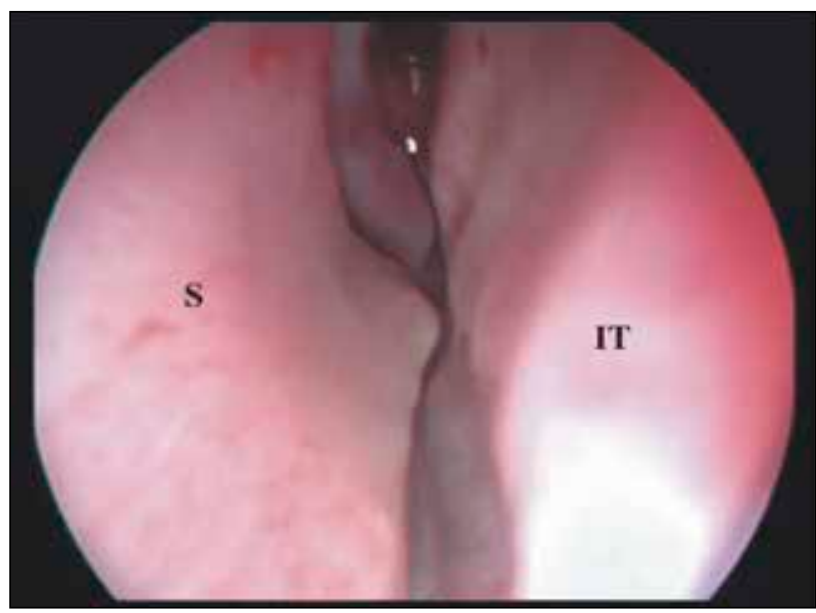

Figure 1 Nasal septum deviation ( $\mathrm{S}$ - septum; IT - inferior turbinate) tween $2.4-5.2 \mathrm{~mm} / \mathrm{min}$ (average $=3.8$ ), and MCTT between 17.6 and 48.0 minutes (average $=32.8)^{13}$.

Moreover, MCC also differ in a population depending on the age. Birch and Elbrnd have shown that MCTT between 4 and 18 years would be of 15 minutes, and is reduced to 10 minutes in people over 18 years ${ }^{13}$. In his turn, Passali has emphasized a MCTT variable between 7.7 and 12.3 minutes in children aged between 3 and 12 years, and between $9.6-15.4$ in adults aged between 19 and 74 years $^{14}$.

\section{ASSESSMENT AND DIAGNOSIS OF NASAL OBSTRUCTION}

Since the phenomenon of nasal obstruction can be due to various diseases, correct assessment of the patient is very important. The anamnesis may guide the doctor towards the cause of occurrence of nasal obstruction.

The classic clinical examination performed using anterior and posterior rhinoscopy can provide information on the appearance of the nasal mucosa, on the existence of pathologic secretions or polypous and/or tumoral masses in the nasal fossae and the rhinopharynx, or can identify septal deviations or increases in volume of the inferior nasal turbinates mucosa.

Nevertheless, one must consider that both anterior and posterior rhinoscopy cannot help in establishing the correct diagnosis ${ }^{15,16}$.

The nasal endoscopic exam can determine the presence of a rhinosinusal pathology with more than $38.7 \%$ compared with rhinoscopy ${ }^{11}$. This examination can identify certain anatomical variants (e.g. septal deviations - Figure 1, hypertrophies of the tails of inferior nasal turbinates - Figure 2, concha bullosa - Figure 3, etc.) or inflammatory or infectious signs (e.g. serous or mucopurulent secretions, crusts, ostial obstructions) (Figure 4), the presence of polypous or tumoral masses ${ }^{1,17-20}$.

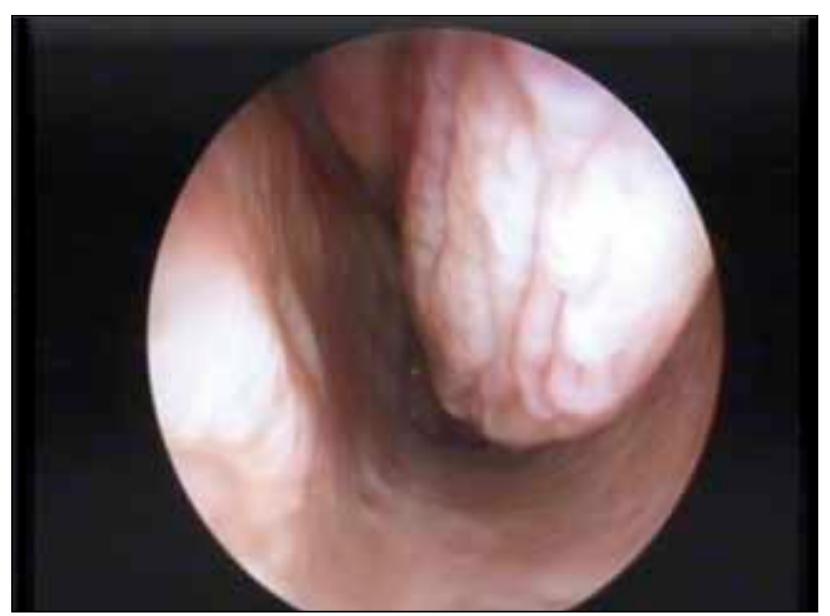

Figure 2 Inferior turbinate hypertrophy (left nostril) 


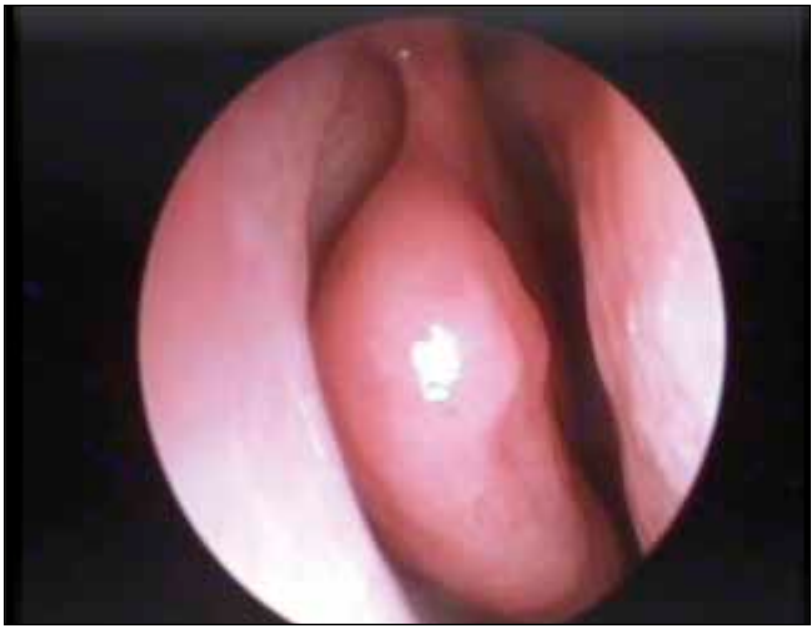

Figure 3 Concha bullosa (middle turbinate; right nostril)
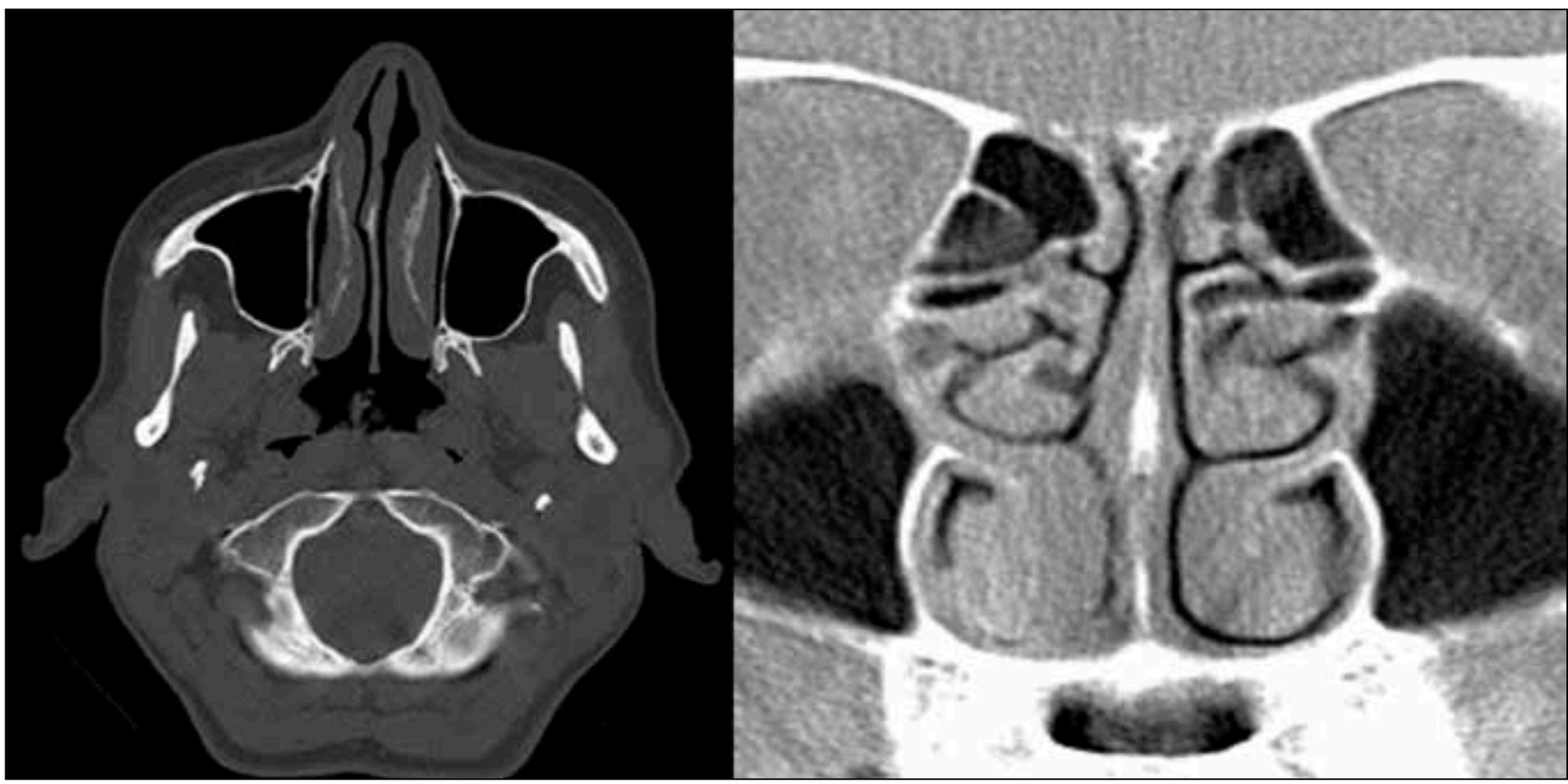

Figure 5 Cranio-facial CT scan, axial and coronal slices - inferior turbinates hypertrophy

Imaging evaluation (simple radiography, computed tomography - CT or magnetic resonance imaging MRI) must always be correlated with the symptoms and the clinical evaluation ${ }^{21,22}$ (Figures 5 and 6 ). There are cases when the appearance of the cranio-facial CT does not match the patient's symptoms ${ }^{22}$.

Objective functional examination of the value of the nasal obstruction is particularly important for identifying bone or mucosal involvement, especially in patients in whom surgical treatment is taken into account $^{1,23,24}$. This examination can be performed by means of: rhinomanometry (anterior, posterior, fourphase), acoustic rhinometry, or peak nasal inspiratory flow (PNIF) ${ }^{25-30}$ (Figure 7, Figure 8, Figure 9, Figure 10) .

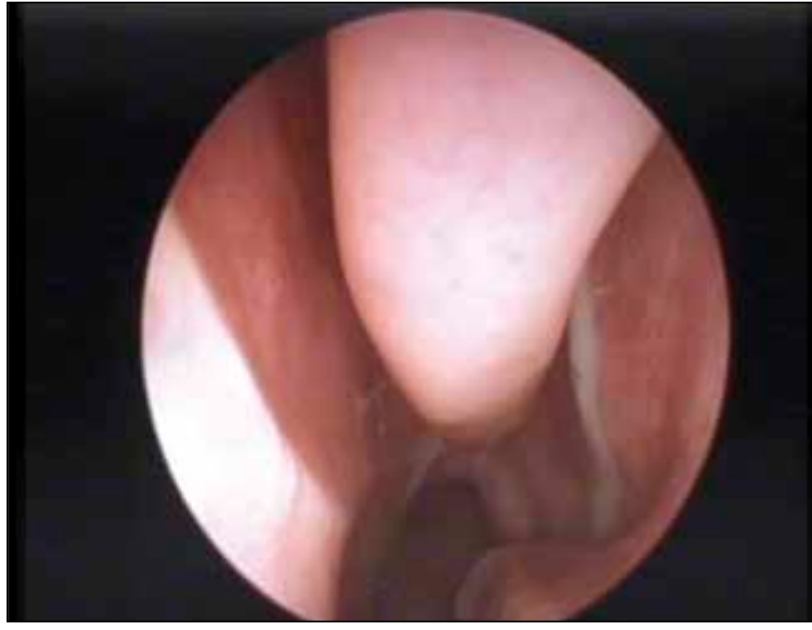

Figure 4 Mucopurulent secretion in the area of the left middle meatus

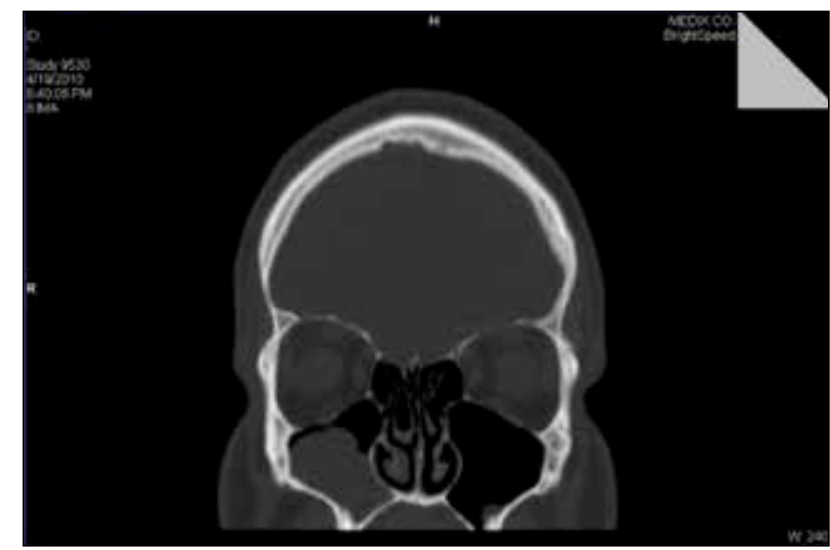

Figure 6 Cranio-facial CT scan, coronal slice, revealing a right maxillary rhinosinusitis 


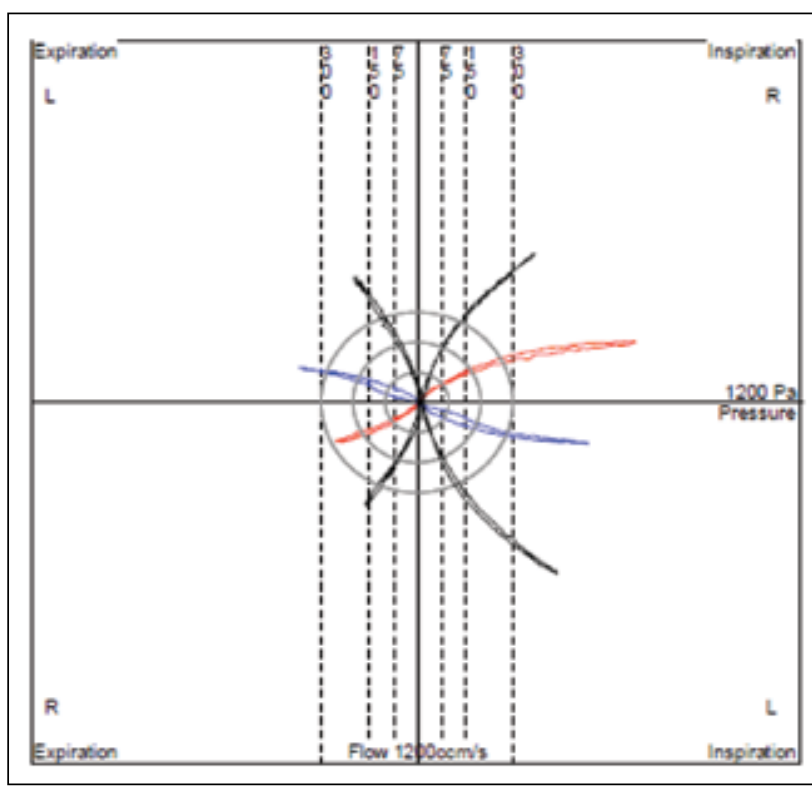

Figure 7 4-Phase Rhinomanometry: the distance between the first measurements (red and blue) and the second measurements (black) shows the high degree of pure mucosal congestion

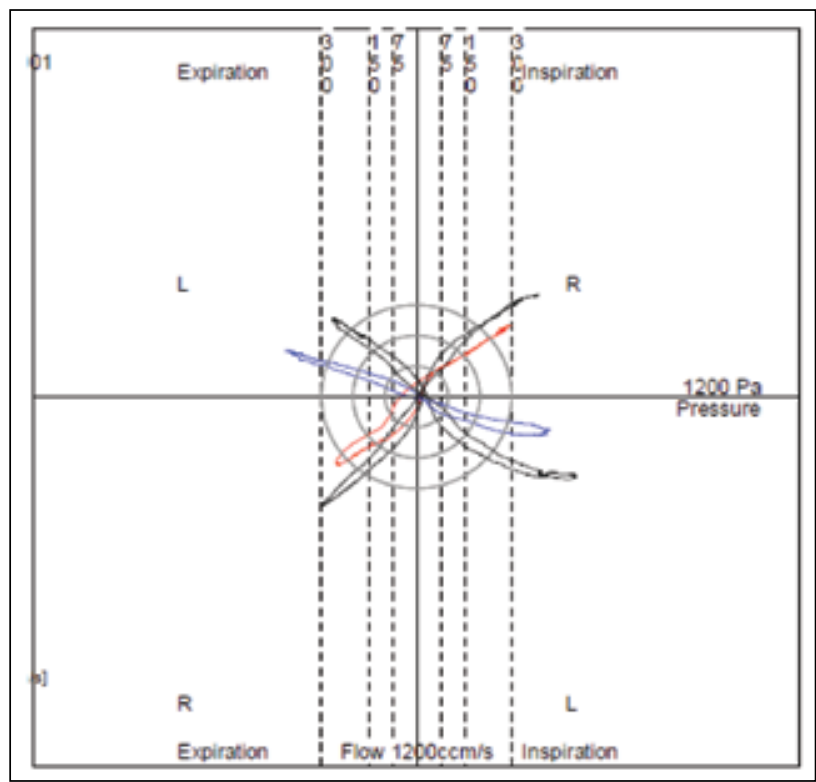

Figure 9 4-Phase Rhinomanometry result suggesting a degree of bone hypertrophy of the inferior turbinate

\section{TREATMENT OF THE NASAL OBSTRUCTION}

\footnotetext{
Monosymptomatic nasal obstruction without septal deviation

This type of nasal obstruction is mainly due to the hypertrophy of the inferior nasal turbinates.

Local vasoconstrictors are sympathomimetic substances that stimulate alpha and beta adrenergic receptors (e.g. ephedrine, pseudoephedrine, mescaline).
}

It is known that nasal vasculature consists of two net-

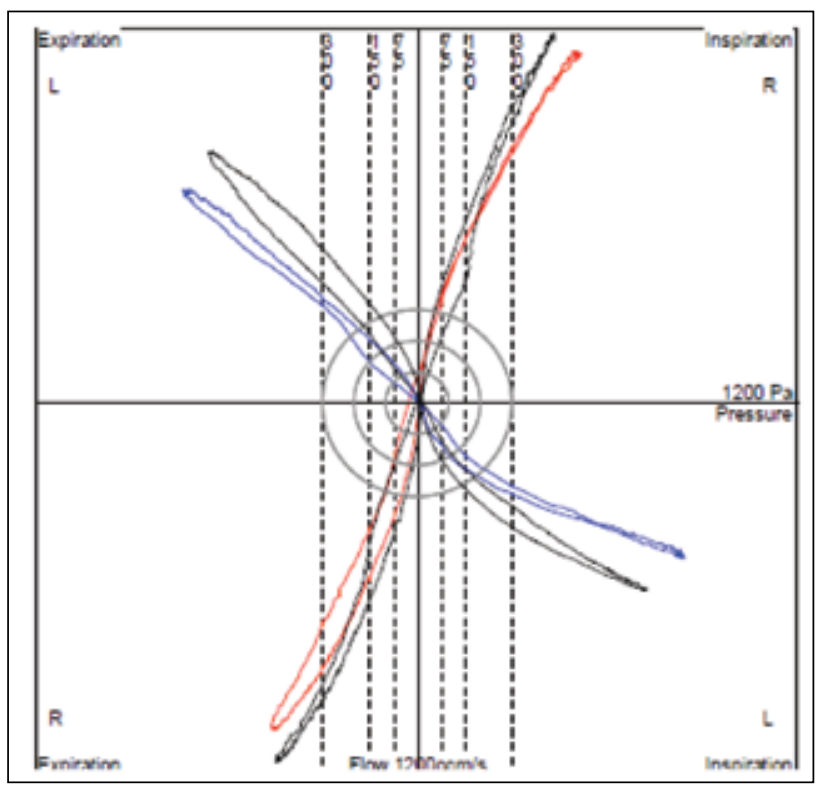

Figure 8 Septal deviation on the left side

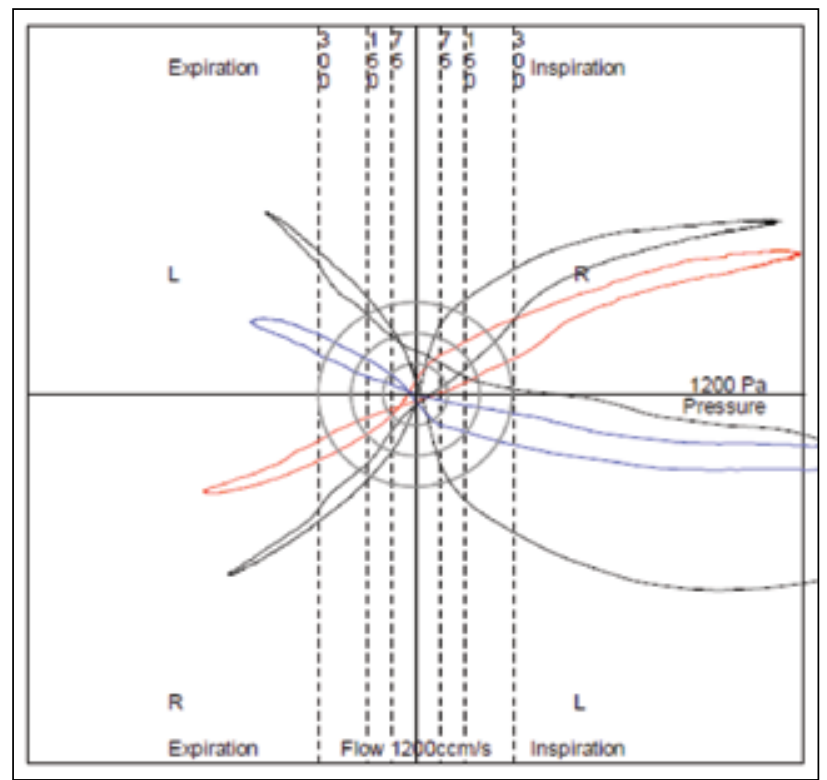

Figure 10 Nasal valve phenomenon

works: arteries and arterioles (resistance vessels), cavernous plexuses and veins located in the nasal turbinates mucosa and on the nasal septum. A dense network of sympathetic nerve fibers, acting as adrenergic receptors, wraps around the resistance vessels.

Adrenergic receptors are of two types: alpha, the majority, with a vasoconstrictor role, and beta, a minority, acting as vasodilators. Alpha adrenergic receptors are sympathomimetic agents releasing norepinephrine neurotransmitters by two mechanisms - a direct one, by direct action on alpha receptors, and an indirect one, by an action of norepinephrine storage $\mathrm{e}^{31,32}$. 
By stimulation of adrenergic receptors located in the nasal mucosa and because of the rich vasculature at this level, the occurrence of nasal congestion by vasodilation, translated into the phenomenon of obstruction, is explained ${ }^{15,33}$.

On the pharmaceutical market, two types of local vasoconstrictors are found: amines and imidazoles. Therapy with topical vasoconstrictors is, generally, efficient, but the phenomenon of rebound is well known when treatment is interrupted ${ }^{32}$. Moreover, used in excess, these substances can cause irritation of the nasal mucosa, leading to the occurrence of drug-induced rhinitis ${ }^{34}$.

This class of drugs is contraindicated in patients with cardiovascular disorders (arterial hypertension, cardiopathies, etc.), hyperthyroidism, in pregnancy.

Oral or local antihistamines may be administered successfully in patients with allergic rhinitis ${ }^{35,36}$.

Menthol derivatives are monocyclic alcoholic compounds extracted from various species of mint (Mentha piperita or Mentha arvensis). These compounds have a characteristic odor and a reassuring effect of relief on the nasal mucosa, by the occurrence of a thermal effect followed by vasodilation ${ }^{37,38}$.

In cases where drug therapy does not bring satisfactory results, a series of surgical therapeutics are required. Over time, various techniques of reduction of the inferior turbinates mucosa volume have been described: diathermocoagulation, partial or total turbinectomy, cryotherapy, laser volumetric reduction (diode, CO2, KTP-Yag) or radiofrequency ${ }^{39-45}$.

Holmes has classified the hypertrophy of the inferior nasal turbinates into five groups ${ }^{46}$ :

1. Compensatory hypertrophy of a septal concavity

2. Hypertrophy of the turbinate skeleton

3. Hypertrophy of the head of the inferior turbinate (Figure 11)

4. Caudal hypertrophy (Figure 12)

5. Global hypertrophy of the turbinate

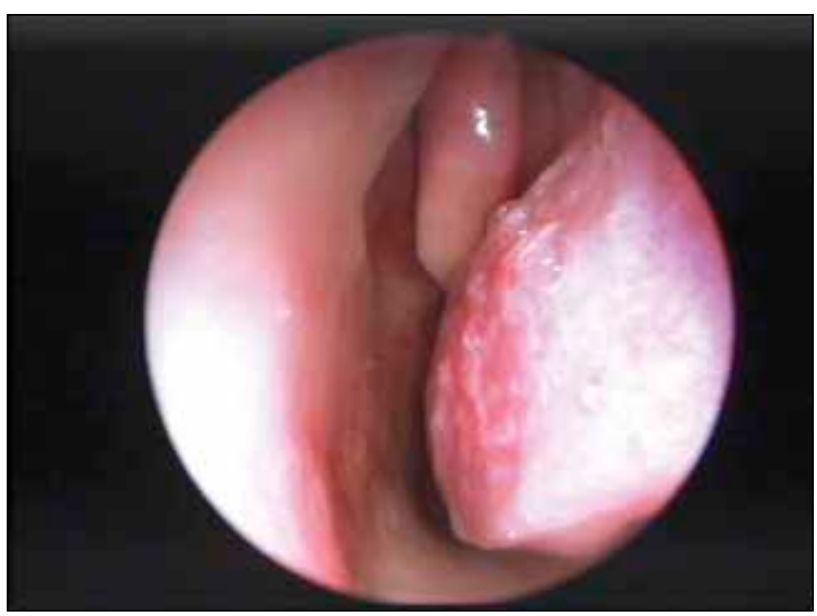

Figure 11 Hypertrophy of the cranial part of the left inferior turbinate
Diathermocoagulation aims to reduce vascularization of the inferior nasal turbinates, and it was first introduced in 1845 by Heider and Crusel ${ }^{47}$. In 1871, Voltini performed electrocautery using the galvanic current ${ }^{48}$. In 1922, the same type of intervention was performed using radiofrequency ${ }^{49}$. Since it is a tissue destruction, there is a risk of forming crusts, of developing atrophy, or of bleeding ${ }^{50,51}$. With the evolution of the technique, the use of bipolar diathermy or coblation, with a much lower temperature, adjacent tissue lesions and the bleeding risk are low ${ }^{52}$.

Chemical cauterization of the inferior nasal turbinates implied the application of trichloracetic acid onto the turbinate mucosa $a^{47,50}$. This technique, frequently used in the nineteenth century, has begun to lose ground and to be used increasingly rarely, due to the necrosis produced and the risk of occurrence of atrophic rhinitis $^{53,54}$. New studies highlight the effectiveness of using silver nitrate, a significant improvement in symptoms being observed in 70-90\% of the cases $^{4,55-58}$.

Partial turbinectomy was first introduced in practice by Jarvis in 1882, who practiced partial turbinectomy ${ }^{59}$, and it is usually indicated in turbinate bone hypertrophies. Later, Holmes and Jones became advocates of total turbinectomy ${ }^{46,60}$. Considering the complications that may arise (bleeding, crusts, synechiae, atrophic rhinitis, empty nose syndrome, etc. ${ }^{47,61-65}$ ), this technique is only reserved for cases with bone hypertrophy, or when minimally invasive laser therapy or radiofrequency do not give the expected results.

Lateropexy was first introduced by Killian in 1904 and consists in fracturing the bone of the inferior nasal turbinate and moving it towards the maxillary sinus after partial removal of the sinus lateral wall ${ }^{47,66}$.

Cryosurgery consists in applying nitrous oxide in the mucosa of the inferior nasal turbinates, the technique being used for the first time in 1970 by Ozenberger ${ }^{67}$. Over time, this type of intervention has been abandoned due to lack of long-term beneficial results ${ }^{68}$.

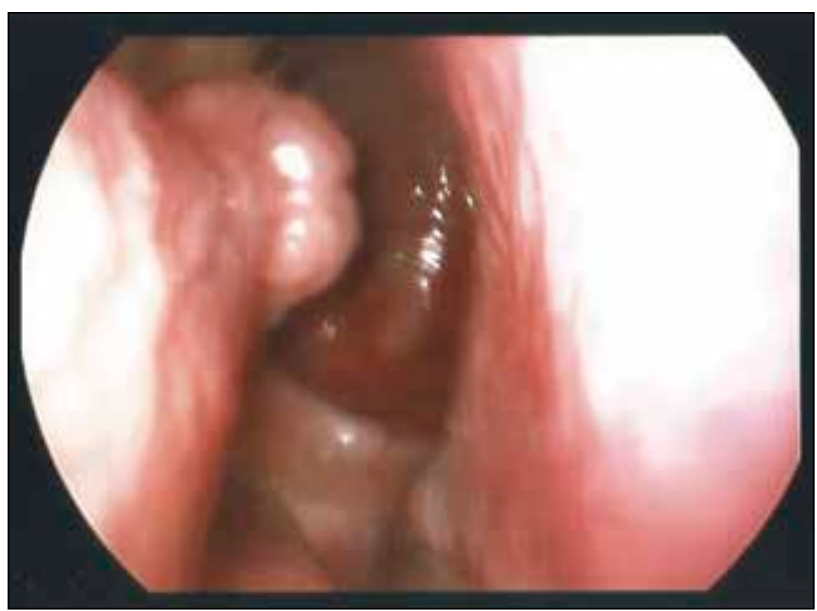

Figure 12 Hypertrophy of the caudal part of the right inferior turbinate 
Turbinoplasty offers the possibility of keeping the integrity and normal functioning of the inferior nasal turbinate mucosa ${ }^{47,69}$. Also, the risk of postoperative bleeding and of developing crusts is diminished. The surgical technique consists in the upward luxation of the turbinate and performing an "L"-shaped incision on the free edge. Part of the bone segment of the turbinate is excised with the biting forceps.

Laser volumetric reduction of the inferior nasal turbinate mucosa. Laser surgery of the inferior nasal turbinates was first introduced into medical practice in 1977 by Lenz who used the argon laser ${ }^{70,71}$. Since the 80 s, other types of laser have been developed, such as the $\mathrm{CO} 2$, KTP, Nd:Yag lasers or the diode laser ${ }^{72-76}$. Of all these, the most frequently used are the $\mathrm{CO} 2$ laser and the diode laser.

The CO2 laser is used with a power range between 0 and $30 \mathrm{~W}$, and it can be used with continuous or pulsatile wave. The degree of in-depth injury is greatly diminished when using the pulsatile mode. Due to the impossibility of using a fiber, the access towards the tail of the inferior nasal turbinate is hampered, the effectiveness of the therapy being thus low in the respective area. Numerous studies in the literature highlight medium and long-term effectiveness of the volumetric reduction of the inferior nasal turbinates mucosa with the $\mathrm{CO} 2$ laser $^{77,78}$.

The temperature created by the CO2 laser on the tissue surface may reach up to $500^{\circ} \mathrm{C}$. By comparison, the argon laser causes a temperature up to $3000^{\circ} \mathrm{C}$.

Radiofrequency volumetric reduction of the inferior nasal turbinate mucosa. Radiofrequency surgery was first introduced into practice by Powell, in the treatment of respiratory sleep disorders ${ }^{79}$. Subsequently, radiofrequency has also been used for the treatment of chronic hypertrophic rhinitis. By its application to the depth of the tissue and the emanated temperature of only $75^{\circ} \mathrm{C}$, the main advantage of radiofrequency surgery is the preservation of the normal functionality of the nasal mucosa and the mucociliary clearance. ${ }^{80,81}$

In the literature, there are studies that show an improvement of up to $100 \%$ of nasal breathing after radiofrequency volumetric reduction of the inferior nasal turbinate mucosa. For example, Speciale demonstrated, in the study carried out in 2000 on a group of 240 patients, a significant reduction in nasal obstruction (of $100 \%) 1$ month and 3 months after surgery ${ }^{82}$. Moreover, Smith emphasized a reduction in the phenomenon of nasal obstruction of up to $90 \%$ in the first 3 weeks postoperatively and of $100 \%$ in the first 8 weeks ${ }^{83}$.

Vogt and Enache conducted a study in 2012 on a group of 150 patients who presented a hypertrophy of the inferior nasal turbinates, in whom they evaluated rhinomanometrically the effectiveness of radiofrequency turbinate surgery 2 months postoperatively ${ }^{84}$. The results showed that the airflow measured at $150 \mathrm{~Pa}$ presented a significant increase ( $p$-value $<0.01$ ), while the average value of the inspiratory logarithmic resistance decreased from 1.12 preoperatively to 0.83 postoperatively (p-value $<0.05)^{84}$ (Figure 13).

\section{Nasal obstruction with a deviated septum}

The only human physiological breathing at rest is nasal breathing.

The normality of breathing is a balanced game between the nasal cycle and the nasoseptal valve $e^{7,10}$. Their

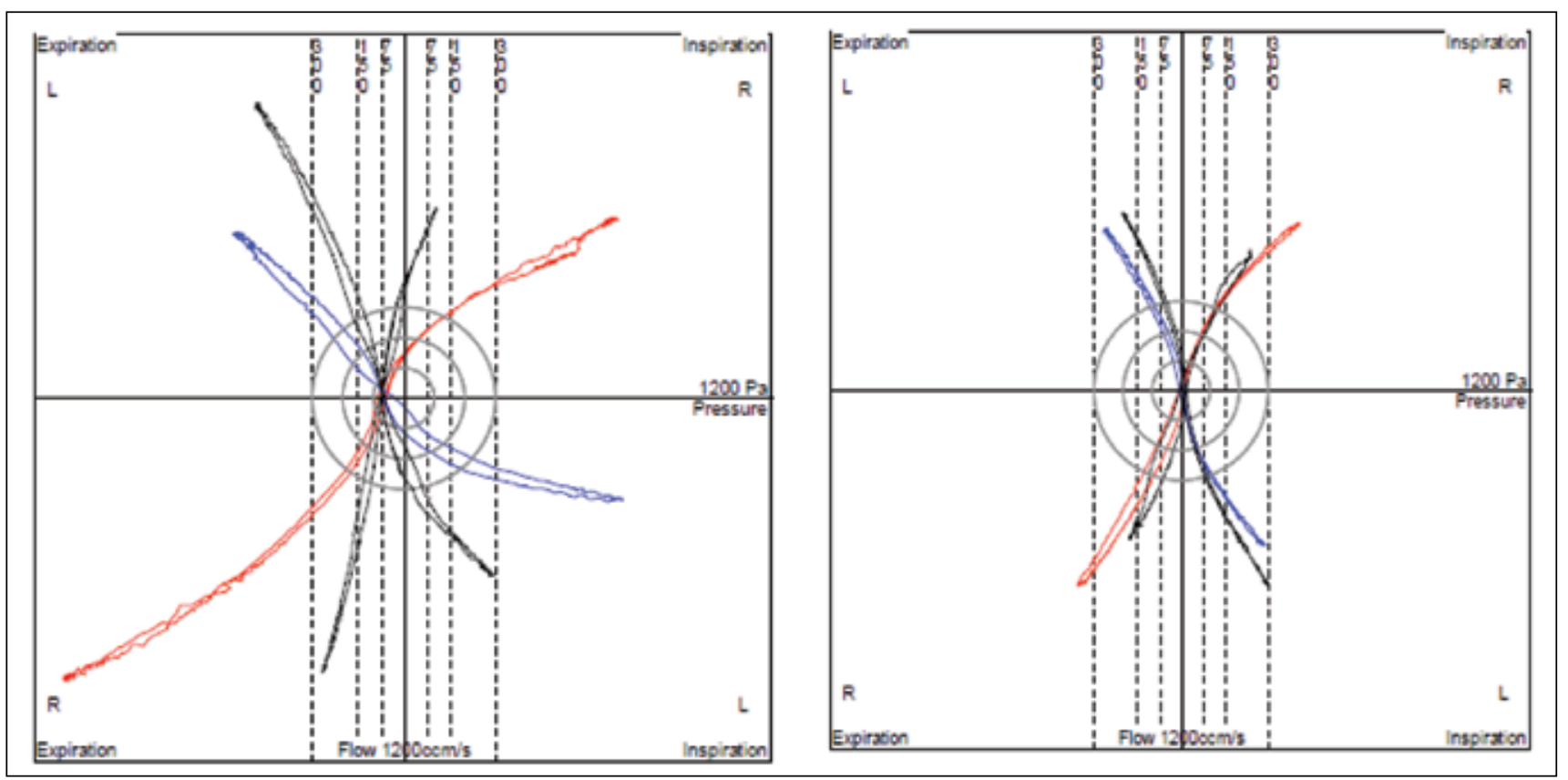

Figure 13 Rhinomanometric results before and 2 months after surgery 
structures are mobile, flexible, being regulated by the airflow. There are four situations in which this breathing balance can be disrupted and require corrective surgery:

- Lateral deviation of the nasal septum associated with a functional deficiency of the upper lateral cartilage;

- Abnormalities of the external slope of the nasal valve followed by inspiratory collapse;

- A modified nasal valve angle (normal bewteen 10 $\left.-15^{\circ}\right)$

- Deficiency of convergence adjustment of the nasal valve structures due to motor trigeminal nerve disorders.

Three corrective surgical techniques are described:

- Submucosal resection of the nasal septum;

- Repositioning of the nasal septum (Killian's technique);

- Septoplasty (Cottle's technique).

So far there are no studies with conclusive results regarding the moment of association of the nasal septum surgery with that of the inferior nasal turbinates. We may say that associating turbinate surgery with nasal septum surgery has no consistent scientific reasons.

According to Mladina, there are 7 types of septal deviations, each type having specific clinical implications $^{85,86}$ :

- Type 1 - vertical deviation of the nasal septum located in the nasal valve area; it does not interfere with the normal ventilatory function.

- Type 2 - vertical deviation of the nasal septum located in the nasal valve area, with disruption of the normal breathing functionality.

- Type 3-vertical deviation located near the head of the inferior nasal turbinate.

- Type 4-there are two vertical deflections in the nasal septum, one in the nasal valve area and the second on the opposite side, near the head of the inferior nasal turbinate.

- Type 5 - Unilateral basal septal crest, without changes in the nasal septum at the level of the contralateral nasal cavity.

- Type 6 - the presence of a horizontal deformity represented by a anterior basal septal crest (it usually makes contact with the inferior nasal turbinate mucosa); on the opposite side, one can notice a "groove" located between the intermaxillary bone wing and the septum.

- Type 7 -combinations of previous types.

From personal observations, we notice that, after a properly performed septoplasty, normalization of the airflow on both nasal fossae was restored in more than $70 \%$ of the cases. This phenomenon occurred by the return to normal of the hypertrophic mucosa of the nasal turbinates, under the influence of inspired air (oxygen), this being the natural stimulus of respiratory physiology.

Nevertheless, in $30 \%$ of the cases, it was about a bone hypertrophy of the inferior nasal turbinate or another cause (e.g. concha bullosa). Preoperative imaging and, respectively, rhinomanometry are edifying in these cases and only based on them is the septoturbinate surgery at the same time justified.

\section{Nasal obstruction and the septal-pyramidal devia- tion}

Monosymptomatic nasal obstruction may be associated to a change in the nasal pyramid aesthetics.

In these cases, functional and aesthetic correction is recommended to be done during the same surgery.

The surgical concept of functional and aesthetic septorhinoplasty is the only one that can ensure the respiratory and aesthetic comfort. The technique of election in these cases is the one described by Cottle in 1946, which consists of a septorhinoplasty by modelling osteo-cartilaginous disarticulation ${ }^{87,88}$.

Without going into the details of the surgical technique, we must however mention that the aesthetician surgeon should be familiar with the endonasal anatomy and pathology, in order not to compromise functionality for aesthetics. Otherwise, the patient will need a reoperation performed by the rhinologist for the recovery of the respiratory comfort.

Complications in the case of rhino-septoplasty (e.g. preserving an inferior septal crest when it exists, septo-turbinate synechiae, nostril inequality, nasal valve pathology - nostril collapse, etc.) are possible when performed by a rhinologist, and may be very common when performed by an aesthetician surgeon who does not investigate the patient in an otorhinolaryngological manner (nasal endoscopic exam, imaging, rhinomanometry). At present, in France, there is a conflict on this issue between rhinologists and plastic surgeons.

\section{Nasal obstruction and nasal valve pathology}

The clinical manifestation of nasal valve insufficiency is the nostril collapse. In respiratory dynamics, inspiratory clamping of the lobe is observed at the level of the triangular cartilages (the upper third), concomitantly with a desynchronization of the dilator muscles of the nose wing. This situation can also be associated with changes in the nasal turbinate, hypertrophies of the middle nasal turbinate (concha bullosa) or deviations of the nasal septum.

In medical practice, two classic situations may be described: tension nose, cicatricial nose.

Tension nose is manifested by excessive growth of the quadrangular cartilage, which translates into an overgrowth of the dorsum nasi and the movement of the alar cartilage anteriorly and sometimes inferiorly ${ }^{89}$. 
This usually occurs in individuals with elongated facies, maxillary endognatia and labial incompetence. In these patients, pyriform orifices are narrow, the upper lip is drawn up and out (appearance of a "visor"). Moreover, an oromandibular dystonia whenever the patient tries to correct the labial occlusion.

The correction is only surgical and several techniques are described. In the case of a tension nose, but without maxillary dysmorphia, rhinoplasty of reduction and advancement of the lobule is sufficient. When a maxillo-facial dysmorphia coexists, the above-mentioned correction requires in addition a vertical reduction genioplasty ${ }^{90}$.

Cicatricial nose can occur as a result of the doublearch rift of the septo-triangular vault. The collapse can manifest only during inspiration or it is permanent. In the first case, a reconstruction can be done. In the second case, when the lack of triangular cartilages is associated, using an auricular cartilage graft is recommended.

Nasal valve syndrome can also occur in the absence of nasal surgical or traumatic history, and may be due to certain hereditary anatomical features. The main symptom is nasal obstruction, that resolves by pulling laterally the nasal valve area (Cottle's maneuver) or/ and by raising the nasal lobule.

4-phase rhinomanometry is the best to establish the existence of a nasal valve syndrome, as we have shown in Figure 10.

The main treatment for this disorder is the surgical one. At present, there are various techniques of correction of the alar insufficiency, the indication being made depending on the anatomical configuration of the nose and the severity of the alar collapse.

In cases where surgery is avoided by the patient, nasal dilators can be used during sleep.

\section{Other causes of nasal obstruction}

Besides those described above, there are also other causes that can lead to the occurrence of monosymptomatic nasal obstruction: polyps, concha bullosa, fibrous dysplasia, intranasal foreign body, unilateral choanal imperforation or tumoral masses. In all these cases, surgery is the therapy of choice.

Rhinopharynx cancer onset may translate into a phenomenon of unilateral, monosymptomatic nasal obstruction. Depending on the symptomatic type and topographic location of the onset of the disease, nasal obstruction may be associated with phenomena of tubal dysfunction, epistaxis. A characteristic is the resistance to vasoconstrictors of the obstructive phenomenon. The biopsy with histopathological examination is the one to establish the positive diagnosis, the treatment being chemo-radiotherapeutic.

\section{CONCLUSIONS}

Monosymptomatic nasal obstruction is one of the most frequent symptoms encountered in the ENT practice.

Correctly performed anamnesis, clinical and paraclinical evaluations can help determine the definite diagnosis and choose the therapeutic strategy indicated in each individual case.

\section{REFERENCES}

1. Krouse J., Lund V., Fokkens W., Meltzer E.O. - Diagnositic strategies in nasal congestion. Int J Gen Med., 2010;3:59-67.

2. Fokkens W., Lund V., Mullol J. - European position paper on rhinosinusitis and nasal polyps 2007. Rhinol Suppl., 2007;(Suppl20):1-136.

3. Van Spronsen E., Ingels K.J., Jansen A.H., Graamans K., Fokkens W.J. Evidence-based recommendations regarding the differential diagnosis and assessment of nasal congestion: using the new GRADE system. Allergy, 2008;63(7):820-833.

4. Aslam M.J., Aslam M.A., Khan A.S., Hussain A., Sharif A. - Treatment of nasal obstruction due to hypertrophic inferior turbinates with application of silver nitrate solution. Ann Pak Inst Med Sci., 2009;5(4):201-205.

5. Passali D., Lauriello M., De Fillippi A., Bellussi L. - Comparative study of most recent surgical techniques for the treatment of the hypertrophy of inferior turbinates. Acta Otorhinolaryngol Ital., 1995;15:219-228.

6. Rombaux Ph., Liistro G., Hamoir M., Bertrand B., Aubert G., Verse T., Rodenstein D. - Nasal obstruction and its impact on sleep-related breathing disorders. Rhinology, 2005;43:242-250.

7. Cole P. - Nasal and oral airflow resistors. Arch Otolaryngol Head Neck Surg., 1992;118:790-793.

8. Cole P., Haight J.S.J. - Posture and nasal patency. Am Rev Respir Dis., 1984;129(3):351-354.

9. Cloe P., Haight J.S.J. - Laryngoscope, 1984;94(12 Pt 1):1557-1559.

10. Ferris B.G. Jr., Mead J., Opie L.H. - Partitioning of respiratory flow resistance in man. J Appl Physiol., 1964;19:653-658.

11. Deborah S., Prathibha K.M. - Measurement of nasal mucociliary clearance. Clin Res Pulmonol., 2014;2(2):1019.

12. Williams R., Rankin N., Smith T., et al. - Relationship between humidity and temperature of insipred gas and the function of the airway mucosa. Crit Care Med., 1996;24(11):1920-1929.

13. Pandya V.K., Tiwari R.S. - Nasal mucociliary clearance in health and disease. Indian J Otolaryngol Head Neck Surg., 2006;58(4):332-334.

14. Passali D., Bellussi L., Ciampoli M.B., Seta E.D. - Experiences in the determination of nasal mucociliary transport time. Acta Otolaryngologica, 1984;97:319-323.

15. Bousquet J., Van Cauwenberge P., Khaltaev N. - Allergic rhinitis and its impact on asthma. J Allergy Clin Immunol., 2001;108(Suppl):S147-S334.

16. Bousquet J., Khaltev N., Cruz A.A., et al. - Allergic Rhinitis and its Impact on Asthma (ARIA) 2008 updated (in collaboration with the World Health Organization, GA2LEN and AllerGen). Allergy, 2008;63(Suppl 86):8-160.

17. Levine H.L. - The office diagnosis of nasal and sinus disorders using rigid nasal endoscopy. Otolaryngol Head Neck Surg., 1990;102(4):370373.

18. Batra P.S. - The role of endoscopy in the allergist's office. Curr Allergy Asthma Rep., 2006;6(3):228-231.

19. Lund V.J., Mackay I.S. - Staging in rhinosinusitis. Rhinology, 1993;31(4):183-184. 
20. Meltzer E.O., Hamilos D.L., Hadley J.A., et al. - Rhinosinusitis: developing guidance for clinical trials. J Allergy Clin Immunol., 2006;118(5 Suppl):S17-S61.

21. McNeill E., O'Hara J., Carrie S. - The significance of MRI findings for non-rhinological disease. Clin Otolaryngol., 2006;31 (4):292-296.

22. Krouse J.H. - Computed tomography stage, allergy testing, and quality of life in patients with sinusitis. Otolaryngol Head Neck Surg., 2000;123(4):389-392.

23. Schumacher M.J. - Nasal congestion and airway obstruction: the validity of availabe objective and subjective measures. Curr Allergy Asthma Rep., 2002;2:245-251.

24. Chin D., Marcells G., Malek J., Pratt E., Sacks R., Snidvongs K., Harvey R. - Nasal peak inspiratory flow (NPIF) as a diagnostic tool for differentiating decongestable from structural nasal obstruction. Rhinology, 2014;52(2):116-121. doi:10.4193/Rhin.

25. Hox V., Callebaut I., Bobic S., Jorissen M., Hellings P.W. - Nasal obstruction and smell impairment in nasal polyp disease: correlation between objective and subjective parameters. Rhinology, 2010; 48:426-432.

26. Ottaviano G., Scadding G.K., Coles S., et al. - Peak nasal inspiratory flow; normal range in adult population. Rhinology, 2006;44:32-35.

27. Malm L. - Assessment and staging of nasal polyposis. Acta Otolaryngol., 1997;117:465-467.

28. Vogt K., Jalowayski A.A. - The objective and measurement principles of rhinomanometry. Rhinology, 2010;(Suppl 21):5-6.

29. Vogt K., Shah-Hosseini K., Mosges R., Pallanch J., Hasse W. - New parameters in 4-phase-rhinomanometry, relations between objective findings and the sensation of obstruction. A statistical evaluation of 1580 cases. Rhinology, 2010;(Suppl21):25-31.

30. Vogt K. - Nasal valve diagnosis by 4-phase-rhinomanometry. Rhinology, 2010; (Suppl21):32-34.

31. Piascik M.T., Perez D.M. - Alphal-adrenergic receptors: new insights and directions. J Pharmacol Exp Ther., 2001;298(2):403-410.

32. Johnson D.A., Hricik J.G. - The pharmacology of alpha-adrenergic decongestants. Pharmacotherapy, 1993;13(6 Pt 2):110S-115S; discussion 143S-146S.

33. Baraniuk J.N., Kim D. - Nasonal reflex, the nasal cycle, and sneeze. Curr Alergy Asthma Rep., 2007;7:105-111.

34. Bogacka E. - Decongestantsin treatment of nasal obstruction. Otolaryngol Pol., 1999;53(3):347-352.

35. Bachert C. - A review of the efficacy of desloratadine, fexofenadine, and levocetirizine in the treatment of nasal congestion in patients with allergic rhinitis. Clin Ther., 2009;31(5):921-944. doi: 10.1016/j. clinthera.2009.05.017.

36. Hore I., Georgalas C., Scadding G. - Oral antihistamines for the symptom of nasal obstruction in persistent allergic rhinitis - a systematic review of randomized controlled trials. Clin Exp Allergy, 2005;35(2):207212.

37. Eccles R., Jawad M.S., Morris S. - The effects of oral administration of menthol on nasal resistance to airflow and nasal sensation of airflow in subjects suffering from nasal congestion associated with common cold. J Pharm Pharmacol., 1990;42:652-654.

38. Shah P.P., D'Mello P.M. - A review of medicinal uses and pharmacological effects of Mentha piperita. NPR, 2004;3(4):214-221.

39. Wight R.G., Jones A.S. - Radical trimming of the inferior turbinates and its effect on nasal resistance to airflow. J Laryngol Otol., 1988;102:694-696.

40. Fanous N. - Anterior turbinectomy. A new surgical approach to turbinate hypertrophy: a review of 220 cases. Arch Otolaryngol Head Neck Surg., 1986;112:850-852.

41. Goode R.L. - Surgery of the turbinates. J otolaryngol., 1978;7:262-268.

42. Ozenberger J.M. - Cryosurgery in chronic rhinitis. Laryngoscope, 1970;80:723-734.
43. Janda P., Sroka R., Baumgartner R., Grevers G., Leuning A. - Laser treatment of hyperplastic inferior nasal turbinates. Lasers Surg Med., 2001;28:404-413.

44. Li K.K., Powell N.B., Riley R.W., Troell R.J., Guilleminault C. Radiofrequency volumetric tissue reduction for treatment of turninate hypertrophy: a pilot study. Otolaryngol Head Neck Surg., 1998;119:569-573.

45. Joniau S., Wong I., Rajapaksa S., Carney S.A., Worlmald P.J. - Long term comparison between submucosal cauterisation and powered reduction of the inferior turbinates. Laryngoscope, 2006;116:1612-1616.

46. Holmes C.R. - Hypertrophy of the turbinated bodies. New York Medical Journal, 1900;72:529.

47. Myrthe K.S., Huizing E.H. - Treatment of inferior turbinate pathology: a review and critical evaluation of the different techniques. Rhinology, 2000;38:157-166.

48. Voltini R. - Die Anwendung der Galvanokaustik im innern des Kehlkopfes und Schlundkopfes. Wilhelm Braumuller, Wien, 1871.

49. Bourgeois H., Poyet G. Rev Larynx, 1922;43:883. Bordeaux.

50. Haq E.U. - Surgical reduction of hypertrophied inferior turbinate: a review and critical analysis of different techniques. Pak J Surg., 2014;30(4):355-361.

51. Oluwole M., Mills R.P. - An audit of the early complications of turbinectomy. Ann R Coll Surg Engl., 1994;76(5):339-341.

52. Smith T.L., Correa A.J., Kuo T., Reinisch L. - Radiofrequency tissue ablation of the inferior turbinates using a thermocouple feedback electrode. Laryngoscope, 1999;109(11):1760-1765.

53. Honda K., Ooki K., Makishima K. - Topical application of trichlor-acetic acid as therapy for nasal allergy. Eur Arch Otorhinolaryngol. 1994;251(Suppl 1):S65-S67.

54. Meyer - Histologische beitrage zur Wirkung der Trichlores sigaure und chromsaure. Z Ohrenheilk., 1903;44:81-88.

55. Klasen H.J. - A historical review of the use of silver nitrate in the treatment of burns. II. Renewed interest of silver. Burn, 2000;26(2):131-138.

56. Al-Samarrae S.M. - Treatment of vasomotor rhinitis by local application of silver nitrate. J Laryngol Otol., 1991;105(40):285-287.

57. Latif S., Aslam N. - Treatment of allergic rhinitis by $25 \%$ Silver Nitrate cauterization. Proceeding Sheikh Zayed Postgrad Med Inst., 2004;18(2):69-72

58. Bhargava K.B., Shirali G.N., Abhyankar U.S., et al. - Treatment of allergic and vasomotor rhinitis by the application of different concentration of silver nitrate. J Laryngol Otol., 1992;106(8):699-701.

59. Jarvis W.M.C. - Removal of hypertrophied inferior turbinate by ecasement with cold wire. Arch Laryngol., 1982;3:10-111.

60. Jones M . -Turbinal hypertrophy. Lancet, 1895;2:895.

61. Dawes P.J.D. - Inferior turbinectomy: in the risk of hemorrhage overstressed. Laryngol Otol., 1988;102:590-591.

62. Eliashar R. - Total inferior turbinectomy: operative results and technique. Ann Otol Rhinol Laryngol., 2001;110:700.

63. Odetoyinbo O. - Complications following total inferior turbinectomy; fact or myth? Clin Otolaryngol., 1987;12:361-363.

64. Courtis E.H., Goldwyn R.M. - Resection of obstructing inferior nasal turbinate. Plast Reconstr Surg., 1990;86:152-154.

65. Stenquist M., Kern E.B. - Personal communication. 1997.

66. Fateen M. - Chonco antropaxy (CAP) in vasomotor rhinitis and chronic nasal obstruction. Rhinology, 1967;5:20-24.

67. Ozenberger J.M. - Cryosurgery in chronic rhinitis. Laryngoscope, 1970;83:723-734.

68. Kellerhans J., Schlageter J. - Cryosurgery in vasomotor rhinopathy. Experimental histopathology. Oto Rhinol Laryngol., 1988;38:157-163.

69. Passali D., Lauriello M., Anselmi M., Bellussi L. - Treatment of hypertrophy of the inferior turbinate: Long-term results in 382 patients randomly assigned to therapy. Ann Otol Rhinol Laryngol., 1999;108(6):569-575. 
70. Lenz H., Eicher J., Schafer G., Salk J. - Parameters for argon laser surgery of the lower human turbinates. In vitro experiments. Acta Otolaryngol (Stockholm), 1977;83:360.

71. Lenz H., Eichler J., Knof J., Salk J., Schafer G. - Endonasal Ar+-laser beam guide system and first clinical application in vasomotor rhinitis. Laryngol Rhinol Otol (Stuttgart), 1977;56:749.

72. Mittelman H. - CO2-laser turbinectomies for chronic, obstructive rhinitis. Laser Surg Med., 1982;2:29-36.

73. Katz S., Schmelzer B., Vidts G. - Treatment of the obstructive nose by CO2-laser reduction of the inferior turbinates: technique and results. Am J Rhinol., 2000;14(1):51-55.

74. Levine H.L. - KTP/532 laser for nasal sinus disease. Ann Otol Rhinol Laryngol., 1989;98:46-51.

75. Werner J.A., Rudert H. - Ser Einsatz des Nd:Yag-lasers in der Hals-, Nasen-, Ohrenheilkunde. HNO, 1992;40:248-258.

76. Min Y.G., Kim H.S., Yun Y.S., Kim C.S., Jang Y.J., Jung T.G. - Contact laser turbinate surgery for the treatment of idiopathic rhinitis. Clin Otolaryngol., 1996;21:533-536.

77. Prokopakis E.P., Koudounarakis E.I., Velegrakis G.A. - Efficacy of inferior turbiplasty with the use of $\mathrm{CO}(2)$ laser, radiofrequency, and electrocautery. Am J Rhinol Allergy, 2014;28(3):269-272. doi: 10.2500/ ajra.2014.28.4044.

78. Ungureanu R., Enache R., Sarafoleanu D., Sarafoleanu C. - The efficacy of CO2 laser turbinoplasty in patients with chronic hypertrophic rhinitis assessed using 4-phase-rhinomanometry. Romanian Journal of Rhinology, 2012;2(6):85-89

79. Powell N.B., Riley R.W., Troell R.J., et al. - Radiofrequency volumetric tissue reduction of the palate in subjects with sleep-disorders breathing. Chest, 1998;113:1163-1174.

80. Sapci T., Sahin B., Karavus A., Akbulut U.G. - Comparison of the effects of radiofrequency tissue ablation, $\mathrm{CO} 2$ laser ablation, and partial turbinectomy applications on nasal mucociliary function. Laryngoscope, 2003;113:514-519.

81. Barbieri M., Salami A., Mora F., Barbieri A., Cordone M.P., Baricalla F., Passali F.M., Ralli G., Malloni F., Cassano M., Mora R. - High frequency surgery in the treatment of turbinate hypertrophy: 11 years experience. Acta Otorhinolaryngol Ital., 2003;23:436-439.

82. Speciale R., Rustivo S., Gallina S., Cupido G., Giammanco A.M. - Surgery of the inferior turbinates by radiofrequency. Otorhinolaringologia, 2000;50(2):95-98.

83. Smith T.L., Correa A.J., Kuo T., Reinisch L. - Radiofrequency tissue ablation of the inferior turbinates using a thermocouple feed-back electrode Laryngoscope, 1999;109:1760-1765.

84. Vogt K., Enache R. - Radiofrequency turbinotomy: basic, practice and statistics. Romanian Journal of Rhinology, 2012;2(7):133-138.

85. Mladina R. - The role of maxillar morphology in the development of pathological septal deformities. Rhinology, 1987;25:199-205.

86. Mladina R. - Clinical implications of septal deformities. Romanian Journal of Rhinology, 2012;2(5):10-13.

87. Cottle M.H., Lohring R. - Corrective surgery of the external pyramid and the nasal septum for restoration of normal physiology. Ill Med J., 1946;90:119-131.

88. Jankowski R. - Septorhinoplasty by modeling disarticulation. Fr ORL, 2006;90:225-229.

89. Johnson C.M. Jr, Godin M.S. - The tension nose: open structure rhinoplasty approach. Plast Reconstr Surg., 1995;95(1):43-51.

90. Meyer R. - Secondary Rhinoplasty: Including Reconstruction of the Nose. Second Edition. Springer - Verlag Berlin Heidelberg New York, 2002;pp.275-318. 